\title{
Study on aging of lignin modified asphalt under thermogravimetric conditions
}

\author{
Xin $\mathrm{Fu}^{1}$, Mao $\mathrm{He}^{2}$ and Yuancai Liu ${ }^{*}$ \\ ${ }^{1}$ College of Civil Engineering, Southwest Forestry University, Kunming, Yunnan, 650224, China \\ ${ }^{2}$ College of Civil Engineering, Southwest Forestry University, Kunming, Yunnan, 650224, China
}

\begin{abstract}
In order to study the aging process of lignin-modified asphalt and explore the effect of lignin on the anti-aging performance of base asphalt, 4 sets of lignin-modified asphalt were prepared under different base asphalt, different dosage, temperature and time. Based on the thermal oxidation test (TFOT), dynamic shear rheological test (DSR), thermogravimetric test (TG), and infrared spectroscopy micro-performance test (FTIR), the high-temperature rheological properties and performance of aging lignin-based asphalt with different content were investigated. The changing law of the chemical properties of functional groups. The results show that the addition of lignin to the base asphalt sample increases the complex shear modulus $G^{*}$ and decreases the phase angle $\delta$ compared to the base asphalt sample prepared by the same sample preparation process. In the same sample, with the continuous increase of the test temperature, the complex shear modulus $G^{*}$ of the matrix asphalt before or after aging and the modified asphalt with different content of lignin showed a downward trend. The modification mechanism of lignin on asphalt is essentially that lignin decomposes and reacts with oxygen in the process of thermal oxidative aging, which delays the oxidation reaction of asphalt during aging, so as to achieve the anti-aging effect of asphalt.
\end{abstract}

\section{Introduction}

Asphalt is the main bonding and waterproof material for roads and roofs. Up to today, $94 \%$ of the road pavements built and used in my country are made of asphalt mixture. However, various chemical substances in the asphalt will undergo complex chemical reactions under the action of hot oxygen, which will easily cause the problem of hot oxygen aging and reduce its road performance. Lignin is an amorphous aromatic network polymer containing $25 \%$ non-fossil organic carbon. The cell walls of trees, grasses and many agricultural plants contain a large amount of lignin, which is a renewable biomass resource second only to cellulose in nature, accounting for about $22 \%$ to $29 \%$ of plant weight. Therefore, the effective and reasonable use of lignin as an asphalt modifier can not only improve the performance of asphalt roads, but also ease the use of natural resources. Chinese scholars have also made certain research results on the anti-aging properties of lignin. Wu Wenjuan [1-2] and others analyzed the blending mechanism and aging performance of modified asphalt by infrared spectroscopy and differential scanning calorimetry, and found that the mixture of lignin and asphalt is a physical blend, and lignin is added to the asphalt After that, it can improve the high temperature stability of the asphalt, has a certain antioxidant effect, and can delay the aging process. Cheng Cheng [3-4] pointed out in the short-term aging study of lignin-modified asphalt that $12 \%$ lignin can significantly improve the anti-aging performance of asphalt. Liao Yijian modified asphalt with enzymatic lignin and found that adding enzymatic lignin and ureaformaldehyde modified enzymatic lignin improved the high-temperature performance of asphalt, reduced the low-temperature performance of asphalt, and improved the resistance of asphalt. Aging performance. Traditional research methods can evaluate the anti-aging ability of asphalt, but it is difficult to reveal the component changes of asphalt during the aging process. Therefore, this article uses infrared spectroscopy to analyze the microscopic composition and structure of ligninmodified asphalt during the aging process according to the existing test conditions. Explore the aging mechanism of lignin modified asphalt.

\section{Test materials and test methods}

\subsection{Test materials}

The basic performance indexes of lignin and the main technical indexes of matrix asphalt used in this test are shown in Table 1 and Table 2.

Table 1. Performance Index of Base Asphal

\begin{tabular}{|c|c|c|}
\hline Pilot projects & Test value & $\begin{array}{c}\text { Technical } \\
\text { standard }\end{array}$ \\
\hline $\begin{array}{c}\text { Penetration } \\
\left(25^{\circ} \mathrm{C}, / 0.1 \mathrm{~mm}\right.\end{array}$ & 66.2 & $60 \sim 80$ \\
\hline Softening point $/{ }^{\circ} \mathrm{C}$ & 45.3 & $>45$ \\
\hline
\end{tabular}

\footnotetext{
*Corresponding author's E-mail: 1121702038@qq.com
} 


\begin{tabular}{|c|c|c|}
\hline Ductility at $15^{\circ} \mathrm{C} / \mathrm{cm}$ & $>150$ & $>100$ \\
\hline $\begin{array}{c}\text { TFOT penetration ratio } \\
\left(25^{\circ} \mathrm{C}\right) / \%\end{array}$ & 75.6 & $>60 \%$ \\
\hline $\begin{array}{c}\text { Residual ductility } \\
\left(15^{\circ} \mathrm{C}\right) / \mathrm{cm}\end{array}$ & 133.0 & $>15$ \\
\hline
\end{tabular}

Table 2. Main Technical Indexes of Lignin

\begin{tabular}{|c|c|}
\hline Technical index & Content \\
\hline $\mathrm{PH}$ & $6.8 \sim 8.1$ \\
\hline Exterior color & Brown powder \\
\hline Ash $/ \%$ & 1.2 \\
\hline content $/ \%$ & $85.3 \sim 90.2$ \\
\hline
\end{tabular}

\subsection{Test methods}

Using a synchronous analyzer, nitrogen as a protective gas, at a temperature rise rate of $9.8^{\circ} \mathrm{C} / \mathrm{min}$, conduct pyrolysis experiments on the asphalt samples before and after aging in the temperature range of 30 to $710^{\circ} \mathrm{C}$, and the quality of each sample is controlled at about $5.0 \mathrm{mg}$. Asphalt is an organic polymer material. Infrared spectroscopy is used to analyze the changes in the main functional groups to gain a deeper understanding of its aging process. Test operation process: Before the base asphalt and modified asphalt samples are subjected to the infrared spectrum test, the samples are fully dissolved in petroleum ether solution, and the potassium bromide crystals are fully milled in a mortar according to the ratio of 1:100. Nano-level fine powder makes the sample and potassium bromide mixed evenly. After the solvent evaporates, put it in an oven to dry until there is no moisture, then put it in a desiccator to cool, and leave it in a closed container for later use.

\section{Results and analysis}

\subsection{Thermogravimetric analysis}

The SK matrix asphalt, shell matrix asphalt and two 12\% lignin-modified asphalts were subjected to comparative thermogravimetric analysis tests. The TG analysis results before and after aging are shown in Figure 1 to Figure 4. It can be seen from the figure that the initial decomposition temperature of $\mathrm{SK}$ base asphalt and modified asphalt is around $255^{\circ} \mathrm{C}$, the final decomposition temperature is around $530^{\circ} \mathrm{C}$, and the maximum decomposition temperature is around $460^{\circ} \mathrm{C}$. The initial decomposition temperature of shell matrix asphalt and modified asphalt is around $220^{\circ} \mathrm{C}$, the final decomposition temperature is around $525^{\circ} \mathrm{C}$, and the maximum decomposition temperature is around $455^{\circ} \mathrm{C}$. The pyrolysis parameters are shown in Table 3 . The thermogravimetric TG curves of the two base asphalt and

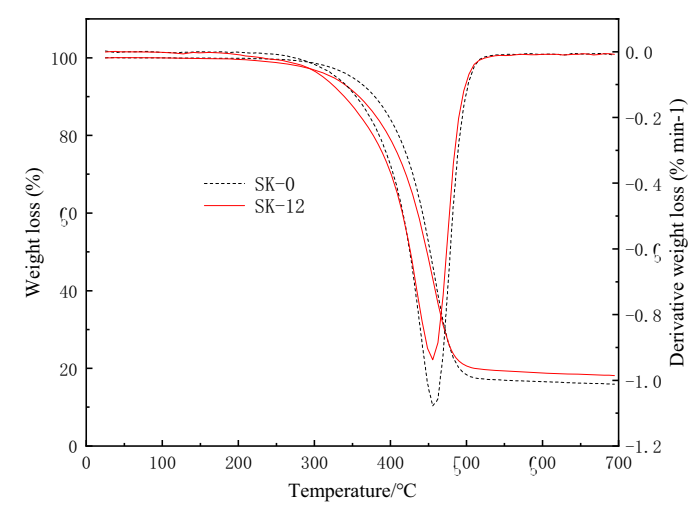

Figure 1. TG image of SK asphalt before aging

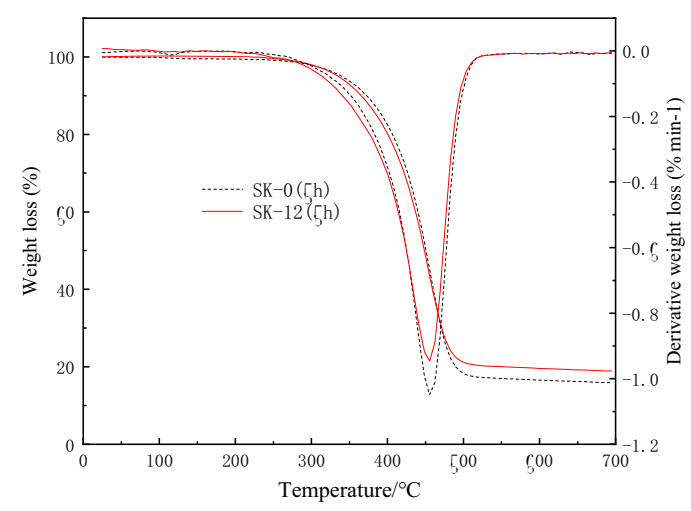

Figure 2. TG image of SK asphalt after aging

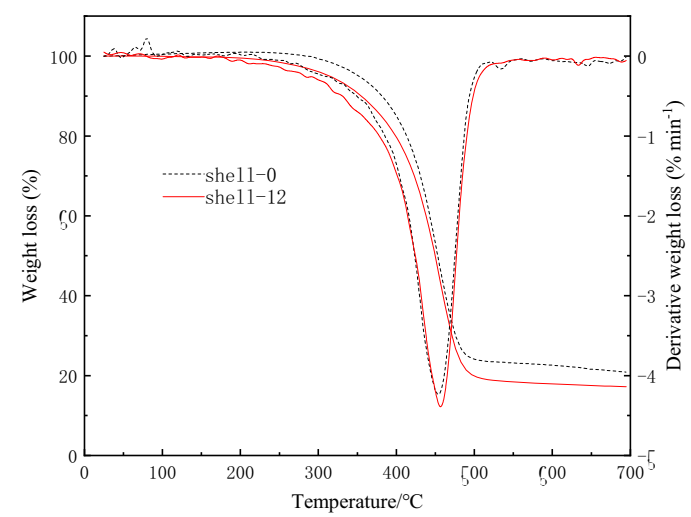

Figure 3. TG image of shell asphalt before aging

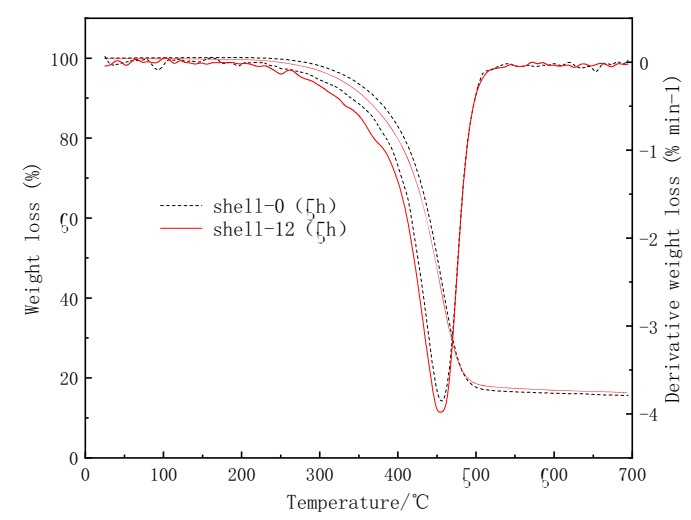

Figure 4. TG image of shell asphalt after aging 
Table 3. Pyrolysis parameters of two kinds of base asphalt samples

\begin{tabular}{|c|c|c|c|c|c|}
\hline \multicolumn{2}{|l|}{ Sample } & SK-0 & SK-12 & shell-0 & shell-12 \\
\hline \multirow{3}{*}{ Starting temperature $/{ }^{\circ} \mathrm{C}$} & Original & 243.47 & 191.75 & 220.98 & 229.30 \\
\hline & TFOT & 200.15 & 188.02 & 176.05 & 191.38 \\
\hline & Difference & -43.32 & -3.73 & -44.93 & -37.92 \\
\hline \multirow{3}{*}{$\begin{array}{l}\text { Maximum decomposition } \\
\text { temperature } /{ }^{\circ} \mathrm{C}\end{array}$} & Original & 457.21 & 455.26 & 454.02 & 456.15 \\
\hline & TFOT & 457.31 & 454.63 & 456.63 & 454.42 \\
\hline & Difference & 0.10 & -0.63 & 2.61 & -1.72 \\
\hline \multirow{3}{*}{$\begin{array}{l}\text { Decomposition completion } \\
\text { temperature } /{ }^{\circ} \mathrm{C}\end{array}$} & Original & 519.23 & 516.25 & 512.30 & 538.93 \\
\hline & TFOT & 550.45 & 525.42 & 554.08 & 544.28 \\
\hline & Difference & 31.22 & 9.17 & 41.78 & 5.35 \\
\hline \multirow{3}{*}{ Thermal weight loss rate $/ \%$} & Original & 85.06 & 82.63 & 79.06 & 84.40 \\
\hline & TFOT & 85.06 & 81.92 & 82.75 & 83.98 \\
\hline & Difference & 0.00 & -0.70 & 3.68 & -0.42 \\
\hline \multirow{3}{*}{$\begin{array}{c}700^{\circ} \mathrm{C} \text { Residual carbon } \\
\text { rate } / \%\end{array}$} & Original & 15.96 & 18.23 & 20.98 & 15.65 \\
\hline & TFOT & 15.96 & 18.96 & 17.38 & 16.28 \\
\hline & Difference & 0.00 & 0.73 & -3.60 & 0.63 \\
\hline
\end{tabular}

lignin-modified asphalt before aging are roughly the same, and both exhibit a pyrolysis stage. It shows that the incorporation of lignin is only a phenomenon of physical blending with asphalt, and there is no chemical reaction of different materials under hot oxygen conditions. After short-term aging, the curve changes of the two lignin-modified asphalts are somewhat different. After aging, the thermal weight loss rate of SK-12 and shell-12 decreased by $0.70 \%$ and $0.42 \%$, respectively, and the carbon residual rate increased at $700^{\circ} \mathrm{C} .0 .73 \%$ and $0.63 \%$, the maximum decomposition temperature of the two lignin-modified asphalts after passing through the film oven decreased by $0.63^{\circ} \mathrm{C}$ and $1.72^{\circ} \mathrm{C}$, respectively. It shows that during the pyrolysis of the two modified asphalts, the free water absorbed in the asphalt with a certain amount of lignin is lost and gradually tends to form coke. Lignin can inhibit the decomposition of asphalt to a certain extent, thereby delaying the aging process of asphalt. However, compared with the base asphalt SK-0 and shell-0 under the same preparation conditions, the modified asphalt exhibits excellent thermal stability. It can be inferred that the $12 \%$ lignin content in both asphalt Certain high temperature resistance characteristics.

The difference is that the initial decomposition temperature of SK base asphalt and its modified asphalt is earlier than that of shell base asphalt and its modified asphalt. This may be due to different asphalt brands. The $12 \%$ SK lignin modified asphalt is due to the physical properties of the material. Blending affects, the molecular components produce parts with poor thermal stability. In the early stage of rapid pyrolysis, the pyrolysis rate of SK-12 is faster. On the one hand, the temperature may affect the type of asphalt, and on the other hand, it may be due to the uniform material The effect of mixing leads to severe degradation of part of lignin, and the content of lignin with a smaller molecular weight increases.
According to the chart, the initial decomposition temperature of SK base asphalt, shell base asphalt and two modified asphalts before aging decreases with the increase of lignin incorporation. It may be related to the $12 \%$ lignin content. Lignin is a three-dimensional network macromolecular structure formed by phenylpropane monomers connected by ether bonds. It begins to thermally decompose at a low starting temperature (about $210^{\circ} \mathrm{C}$ ). However, its complicated spatial structure will relatively hinder the further thermal decomposition process of lignin and asphalt mixture. The gradient of the image gradually becomes steep, indicating that the degradation of lignin gradually slows down with the progress of pyrolysis within a certain temperature range, and the lignin is at a certain level. It can delay the effect of thermal oxygen aging and achieve the expected anti-aging effect.

\subsection{Infrared spectrum test analysis}

The infrared spectrum test results of the aging process of the two base asphalts and their 12\% lignin-modified asphalt samples are shown in Figure 5 and Figure 6.

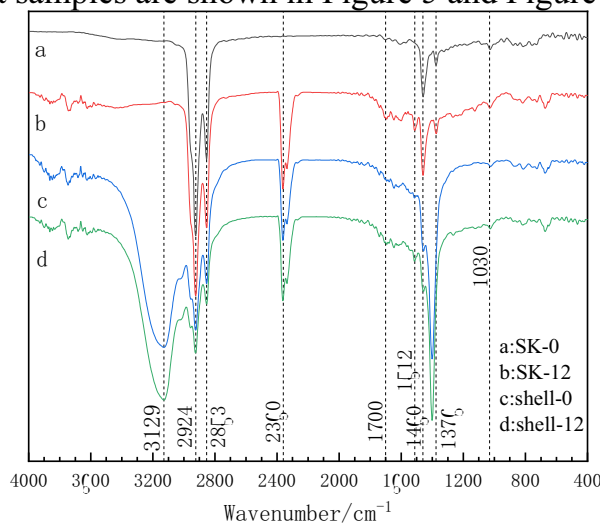

Figure 5. Infrared spectrum of asphalt sample before aging 


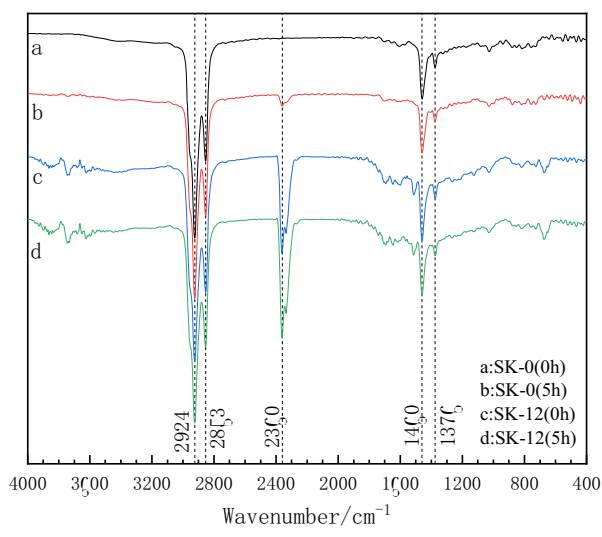

Figure 6. Infrared spectrum of asphalt sample after aging

It can be seen from the infrared spectrum that the intensity of the characteristic absorption peak near 1040 cm-1 of SK-12 and shell-12 lignin-modified asphalt is significantly higher than that of SK-0 and shell-12. By comparing the functional groups of organic compounds The characteristic absorption frequency shows that this absorption peak is the characteristic peak of sulfoxide group $\mathrm{S}=\mathrm{O}$. In addition, a characteristic peak of carboxyl $\mathrm{C}=\mathrm{O}$ appeared near $1750 \mathrm{~cm}-1$. It shows that the unsaturated carbon chain and the oxygen absorption reaction of sulfur occurred in the asphalt during shortterm aging, and the peaks of sulfoxide and carboxyl groups increased after aging, indicating that both the base asphalt and the lignin-modified asphalt have experienced aging.

Both the sulfoxide group and the carbonyl group are the products of the oxidation reaction of the pitch molecules. The larger the index, the more serious the oxidation degree. Due to the different types of asphalt, the overall change trend of shell is the same as SK before and after aging. The test results of sulfoxide group and carboxyl group index are significantly lower than SK, which may be caused by the difference in physical properties of each base asphalt.

\section{Conclusions}

1) The thermogravimetric test shows that the degradation of lignin gradually slows down with the progress of pyrolysis within a certain temperature range, and lignin can delay the effect of thermal oxidative aging to a certain extent and achieve the expected anti-aging effect. 2) The anti-aging mechanism of lignin modified asphalt is essentially that lignin first reacts with oxygen to decompose during the aging process, delaying the oxygen absorption reaction of each asphalt during the aging process.

\section{References}

1. Wu, W.J., The influence of lignin on the aging performance of modified asphalt[J]., Paper Science and Technology, 37(3):20-24. (2012)
2. Wu, W.J., Infrared spectroscopy analysis of ligninmodified asphalt[J]., Journal of Jiangsu University (Natural Science Edition)., 40 (1): 120-124. (2019)

3. Cheng C., Study on short-term aging performance of lignin-modified asphalt[J]., Journal of Southwest Forestry University (Natural Science), 39(3):149154. (2019)

4. Cheng C., High temperature performance test of lignin modified asphalt[J]., Journal of Forestry Engineering, (1):141-147. (2019) 